\title{
THE ABILITY OF AN EXTINGUISHED CS AND A CS GIVEN CONDITIONED INHIBITION TRAINING TO PASS TESTS FOR INHIBITION
}

\author{
A Dissertation Presented to \\ the Faculty of the Graduate School \\ at the University of Missouri in Partial Fulfillment \\ for the Degree of Doctor of Philosophy
}

by

RACHEL A. RICHARDSON

Dr. Todd Schachtman, Dissertation Supervisor

May 2019 
The undersigned, appointed by the Associate Vice Chancellor of the Office of Research and Graduate Studies, have examined the dissertation entitled

\section{THE ABILITY OF AN EXTINGUISHED CS AND A CS GIVEN CONDITIONED INHIBITION TRAINING TO PASS TESTS FOR INHIBITION}

presented by Rachel Richardson,

a candidate for the degree of doctor of philosophy,

and hereby certify that, in their opinion, it is worthy of acceptance.

Professor Rocio Rivera

Professor Kristy vanMarle

Professor Matt Will

Professor Todd Schachtman 
For Dad 


\section{ACKNOWLEGDEMENTS}

Throughout the writing of this dissertation I have received a great deal of support and assistance. I would first like to thank my advisor, Dr. Todd Schachtman, whose expertise was a critical component in this entire process, especially in formulating the research topic and methodology. I want to thank you for your patient guidance and for all of the opportunities I was given to conduct research and further my dissertation at the University of Missouri.

Aside from my advisor, I would like to express sincere appreciation to the rest of my committee: Dr. Rocio Rivera, Dr. Kristy vanMarle, and Dr. Matt Will. Your insightful comments and encouragement were paramount in the successful completion of my dissertation.

I would especially like to thank my dear friend and current lab mate, Paige Michener. You supported me greatly and have been willing to help in any way possible. Appreciation is due to Dr. Diana Klakotskaia, friend and former lab mate. Thank you for your assistance and support over the years. I would like to acknowledge my colleagues from our Cognition and Neuroscience Lab at the University of Missouri for their wonderful assistance.

In addition, I would like to thank my father for his unwavering love and consistent encouragement. You have always been there for me and I know you will continue to be. You raised me to believe in myself and to never stop learning; those traits have greatly attributed to the success of my academic career. 
There are my friends, who were of immense support. Thank you for believing in me as well as providing happy distraction to maintain some sanity throughout my research.

Finally, my sweet Bella, Jaxon, and Cheddar have been a relentless source of drive and inspiration. We have made sacrifices throughout this process but I stand by my promise - it will all be worth it.

Thank you all for helping to build a solid foundation for lifelong achievement. 
TABLE OF CONTENTS

ACKNOWLEDGEMENTS.....................................................

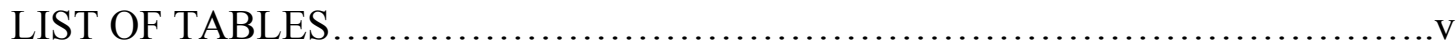

LIST OF FIGURES...................................................................

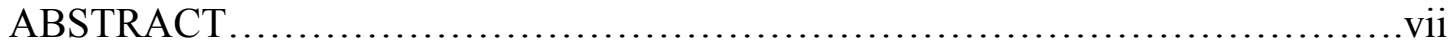

CHAPTER 1: INTRODUCTION.....................................................

Conditioned Inhibition ..................................................

Extinction.................................................................

Extinction versus Conditioned Inhibition ..................................4

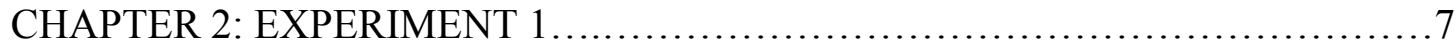

CHAPTER 3: EXPERIMENT 2 ...............................................

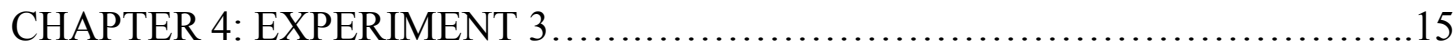

CHAPTER 5: EXPERIMENT 4 ............................................... 18

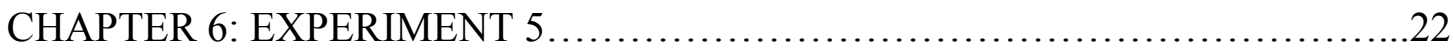

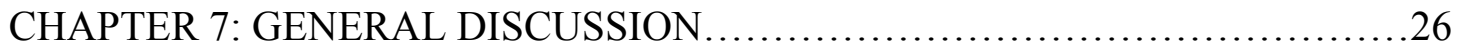

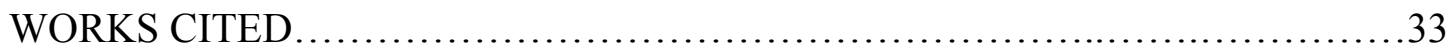

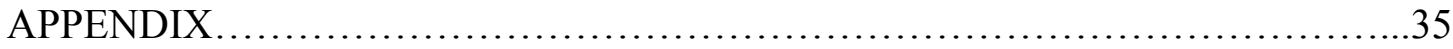

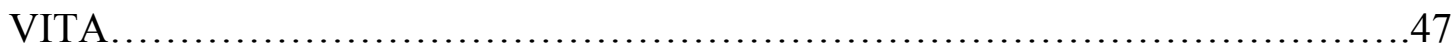




\section{LIST OF TABLES}

Table $\quad$ Page

1 Retardation and Summation Test Experimental Layout......................35

2 Overview of Experiments............................................. 36

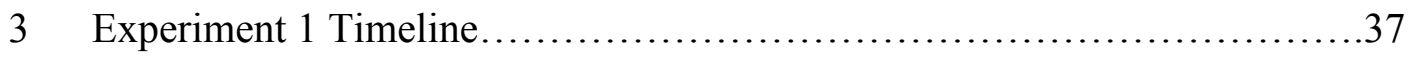

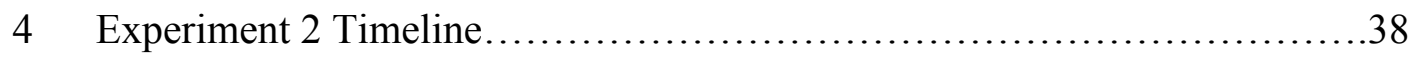

$5 \quad$ Experiment 3 Timeline....................................................

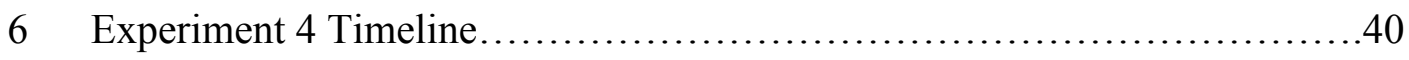

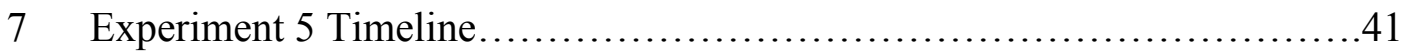




\section{LIST OF FIGURES}

$\begin{array}{ll}\text { Figure } & \text { Page }\end{array}$

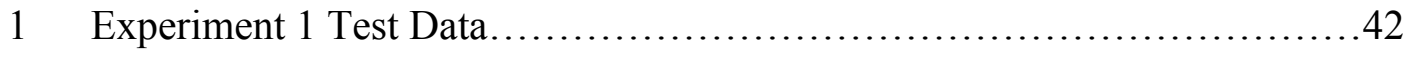

2 Experiment 2 Test Data.............................................. 43

3 Experiment 3 Test Data............................................. 44

$4 \quad$ Experiment 4 Test Data............................................... 45

$5 \quad$ Experiment 5 Test Data............................................... 46 


\begin{abstract}
Conditioned inhibition (CI) is a classical conditioning procedure that results in a conditioned stimulus (CS) that predicts the absence of an unconditioned stimulus (US). A procedure known as Pavlovian conditioned inhibition training is the most common procedure for producing CI. In this procedure, a nontarget CS (CS A) is paired with the US and then CS A is presented with the target CS (CS X) without the US. Therefore, AUS trials and AX-noUS trials are given. CS X acquires inhibitory properties during these AX trials. Research has shown that extinction also produces CI. Extinction occurs when a CS $(\mathrm{CS} \mathrm{X})$ is paired with the US during conditioning and then this CS is presented alone without the US. The Rescorla-Wagner model predicts that the two CSs during AXnoUS trials will compete for learning and this should lead to slow and limited learning about those cues (a loss of excitation for CS A and inhibition acquired for CS X) due to this competition. During extinction trials, CS X does not compete for learning, so the subject should learn rapidly about the CS. The following experiments found that extinction produced less inhibition than Pavlovian conditioned inhibition training.
\end{abstract}




\section{CHAPTER 1:}

\section{INTRODUCTION}

Conditioned inhibition $(\mathrm{CI})$ refers to a classical conditioning procedure that results in a conditioned stimulus (CS) that predicts that the unconditioned stimulus (US) will not occur. For reasons described below, CI has been an enigmatic conditioning phenomenon as the processes underlying inhibition have been debated (e.g., Rescorla 1969; Cotton, Goodall \& Mackintosh, 1982; Miller \& Matzel, 1987). What kind of association underlies CI? If there are many ways to train a CS as an inhibitor, are there different kinds of associations underlying the different ways that CI can be produced? Can conditioned excitation (described below) and CI exist for the same CS (cf. Matzel, Gladstein, \& Miller, 1988)? The present project certainly does not seek to answer these questions, but the project does seek to compare two different training procedures with respect to the extent that inhibition is acquired.

\section{Conditioned Inhibition}

A procedure known as "Pavlovian conditioned inhibition training" is the most common procedure for producing CI. The subject is first given a pairing of the CS (A) and the US. Then, the subject is presented with that CS along with another stimulus (X). During these AX trials, the US is not presented. The second CS, X, soon predicts the absence of the US. The US is presented when A occurs - except when X is also present.

It is difficult to test if the subjects have learned that a CS predicts no US. Using Pavlov's conditioning procedure with dogs as an example: if a tone (A) is paired with food, the dog will then salivate to the tone that predicts food. Such a CS is often called a 
conditioned excitor since the CS predicts that the US will occur. However, it is more challenging to test if the dog has learned that a light (X) predicts that food will not occur. The dog has no reason to salivate before the light is presented and then it certainly has no reason to salivate when the light (which predicts no food) is presented. Without a change in behavior when the light is presented, it is difficult to know whether the dog has learned that the light signals that food will not be presented.

There are two tests used to determine if a CS has become a conditioned inhibitor: summation and retardation tests (see Table 1). They are considered "indirect tests" since they do not involve observing the subject's overt conditioned response to the CS since, as mentioned, this is extremely difficult to observe experimentally. For the retardation test, the CS that has been presumably trained as conditioned inhibitor is now paired with a US. The rationale is that - if the CS is a predictor that the US will not occur, then it should be slow to signal that the US will occur. The acquisition of the excitatory CR will be slow and is compared to a control for which the CS is novel (not inhibitory) at the time of the CS-US pairings. The conditioned inhibitor can be said to pass the retardation test when there is less of a CR to the CS compared to that of the control group.

For the summation test, the CS that has presumably been trained as an inhibitor is presented at test along with a known excitatory CS (a CS such as "CS B" that predicts the US). The rationale is that if the CS is truly an inhibitor it will decrease the magnitude of the excitatory CR to the conditioned excitor, CS B. Therefore, with a summation test for assessing CI, one excitatory CS (A) is used to train CS X as an inhibitor (A-US and AX trials), as mentioned above, while a second excitor (B) is used at test to examine if $\mathrm{X}$ is inhibitory. At test, the subject receives a CS (B) that signals that the US will occur (the 
known excitor) along with a CS that predicts the US will not occur (X). The excitatory CR should be reduced since the subject is receiving one CS that predicts the US and one CS (X) that predicts that the US will not occur. As shown in Table 1, this reduction is compared to a group that is tested only on the known excitor (B). In the latter case, no inhibition is present for the test. Stated differently, the conditioned inhibitor can be said to pass the summation test when there is less of a conditioned response to the test stimulus (inhibitor and known excitor, BX) compared to the CR to the excitor alone (B).

For a CS to be classified as a conditioned inhibitor, it must pass both the summation test and the retardation test. If the CS only passes one of the two tests, there could be some alternative reason for the subject's behavior rather than true inhibitory properties.

\section{Extinction}

Extinction involves giving CS-US pairings (X-US pairings) in which an excitatory $\mathrm{CR}$ develops to $\mathrm{X}$, and then giving CS-alone trials ( $\mathrm{X}$ alone). During CS-US pairings an excitatory X-US association is acquired. Many classical conditioning researchers (e.g., Bouton, 1993, Miller, Kasprow, \& Schachtman, 1986) now acknowledge that the CS-alone extinction trials result the acquisition of an inhibitory association (CS- noUS associations), as first described by Konorski (1967). Indeed, the CS-US association may not even be weakened or lost during the CS-alone extinction trials (a view consistent with the occurrence of "spontaneous recovery"), if the loss of the excitatory CR observed during the CS-alone trials is produced by the acquisition of an inhibitory association. Following the extinction phase, the subjects may possess an X- 
US association and an inhibitory "X-noUS association". There is evidence that a CS can possess both inhibitory and excitatory associations (Matzel, Gladstein, \& Miller, 1988).

It has been known for many decades that Pavlovian CI training can result in a CS that passes both a retardation and summation test (e.g., Rescorla, 1969). Recent research has shown that an extinguished stimulus can pass a retardation test. This research (Bouton, 1986) shows that a CS that is first paired with the US and then undergoes many CS-alone extinction trials, and then is paired with the US once again for the retardation test, slowly comes to show an excitatory CR. This is compared to a control group that is given the final phase of CS-US pairings without earlier conditioning or extinction (see the top of Table 1 again). An extinguished CS also has been shown to pass a summation test (Calton, Mitchell, \& Schachtman, 1996; Schachtman, Threlkeld, \& Meyer, 2000; cf. Aguado, de Brugada, \& Hall, 2001).

For one reason or another, classical conditioning researchers that acknowledge that extinction results in the formation of an inhibitory association do not acknowledge that the CS can become a "net" inhibitor (i.e., expressing more inhibition than excitation). One exception is the work by Schachtman and colleagues (Calton et al., 1996; Schachtman et al., 2000). They posited that an extensively extinguished CS could become a net inhibitor. Calton et al. discovered that an extinguished CS passes both a retardation test and a summation test.

\section{Extinction versus Pavlovian CI training}

If it is accepted that both the Pavlovian CI procedure and extinction can produce $\mathrm{CI}$, it is valuable to ask whether one treatment is more effective at producing inhibition. 
The Rescorla-Wagner (1972; Wagner \& Rescorla, 1972) model of classical conditioning makes predictions regarding the amount of learning that occurs with each procedure. According to the Rescorla-Wagner model, if there is only one stimulus during a conditioning trial, that stimulus is readily learned about and does not have to "compete" for learning with other CSs. If there are two CSs present during a trial, the learning that occurs on that learning trial gets divided between the two CSs. In fact, the RescorlaWagner model was originally developed to account for stimulus competition as well as the occurrence of conditioned inhibition.

In the Pavlovian conditioned inhibition procedure, the subject, as mentioned, first receives A paired with the US, and also is presented with two CSs (A and X) without the US. According to the Rescorla-Wagner model, A will lose excitatory strength on these AX-noUS trials and $\mathrm{X}$ will gain inhibitory strength on these trials. Competition occurs, however, since the more that A undergoes extinction, the less that $\mathrm{X}$ becomes inhibitory (and vice versa). On each trial, learning occurs to some extent, but the Rescorla-Wagner model predicts less change (per trial and overall) compared to the case in which $\mathrm{X}$ is extinguished in the absence of A.

However, with CS-alone extinction trials, only one stimulus (e.g., X) is being presented on "no US trials". This allows for more learning (about the CS) to occur during each trial because the total amount of learning does not have to be split with another CS (an A stimulus is not present). During an extinction procedure, the $\mathrm{X}$ should rapidly lose excitatory strength and/or X should rapidly acquire inhibitory strength. Inhibition could be acquired more rapidly for extinction than Pavlovian conditioned inhibition training. If 
such an outcome occurred, it would be surprising and, yet, at some level, the RescorlaWagner model could be interpreted as predicting it.

However, $\mathrm{X}$ begins the inhibitory phase as an excitor in the case of extinction (XUS trials are followed by $\mathrm{X}$ alone trials), but it starts $\mathrm{CI}$ training as a neutral CS in the case of Pavlovian CI training. Put differently, extinction has one important factor working against rapid learning of expressed inhibition at test: the CS begins the extinction phase as an excitor, while this is not true for Pavlovian CI. The present study compared the inhibition acquired by extinction and Pavlovian CI training. See Table 2 for a list of the focus for each of Experiments 1-5. As mentioned at the proposal meeting, Experiments 1-4 were early experiments while the fifth experiment was conducted as the critical dissertation study. 


\section{CHAPTER 2:}

\section{EXPERIMENT 1}

As mentioned, it is already established that extensive extinction using a conditioned taste aversion procedure causes a CS to pass a summation test (Calton et al., 1992; Schachtman et al., 2000). Some of the present experiments used a procedure modeled after the procedures used in this earlier work. However, it is important to demonstrate that a Pavlovian conditioned inhibition training procedure using a conditioned taste aversion procedure can produce a CS that passes a summation test. Our laboratory has not shown such an effect in published work; and demonstrations of inhibition using conditioned taste aversion have been rare (Delamater, Kruse, Marlin, \& LoLordo, 1986; Espinet, Iraola, Bennett, Mackintosh, 1995). Experiment 1 explored whether rats receiving Pavlovian conditioned inhibition training trials will exhibit successful summation test performance, thereby confirming that the CS is an inhibitor.

Subjects. Approximately 27 naïve, male, Sprague-Dawley rats served as subjects. The body weight range of the rats was 199-232g. Each rat was individually housed in hanging, stainless steel, wire-mesh cages that measured $24 \times 17.7 \times 18.2 \mathrm{~cm}(1 \times \mathrm{w} \mathrm{x} \mathrm{h})$ with ad lib. access to lab chow. Subjects were handled a few times prior to the start of the experiment. The rats were water-deprived prior to the start of the experiment using a graded water-deprivation schedule that ultimately resulted in 15-min of water access each day. Water access occurred in the home cage after each day's treatments. The room housing the animals was on a 16-hr/8-hr light/dark cycle (lights turn on at 7 a.m.) and treatments occurred during the middle of the light portion of the cycle. 
Apparatus. Flavored solutions were presented in a plastic drinking tube (a modified, inverted 50-ml syringe with a metal lick tube attached). All conditioning treatments and testing occurred in the home cage. $\mathrm{LiCl}$ was administered using a 25 -ga, 1.59-cm hypodermic needle. The flavors used were: a $1.5 \%$ decaffeinated coffee solution (Sanka, Pittsburgh, PA), a 3\% apple cider vinegar solution (Heinz; Pittsburgh, PA), a 1\% saline solution and a 1\% saccharin solution (Sigma; St. Louis, MO). In this experiment, vinegar was used as the $\mathrm{X}$ stimulus (the target CS) and coffee served as a "control flavor"; but in Experiment 2 coffee served as the target CS (X) and vinegar served as the control flavor.

Procedures. All procedures for this experiment, as well as Experiments 2-5, occurred during the light portion of the light/dark cycle, and were carried out in accordance with federal animal usage guidelines, and were approved by the University of Missouri Animal Care and Use Committee (ACUC Protocol 9422).

There were two groups, each receiving Pavlovian conditioned inhibition training but half the rats (experimental group) were given CI training with vinegar, the target flavor, and the other half (control group) with a coffee solution, a control flavor. The full procedure can be seen in Table 3. On Day 1, all rats were given 15 -min access to $0.1 \%$ saccharin solution (A) followed by a $0.15 \mathrm{M} \mathrm{LiCl}$ injection delivered i.p. at $1.33 \%$ bodyweight. No treatments occurred on Day 2 to allow the rats to recover from conditioning. However, on this day the rats were given a practice infusion procedure in which $2 \mathrm{ml}$ of water were infused into the rats' mouths using a needleless syringe. On each of Days 3 - 6, all rats were first infused with $2 \mathrm{ml}$ of saccharin (A), then, 15 minutes later, all rats in the PavCI group received 15-min of access to a 3\% vinegar solution (X). 
Rats in the control group received 15 -min of access to a $1.5 \%$ coffee solution (CS Y, a control flavor, instead of $\mathrm{X}$ ). Fifteen minutes were placed between the CS exposures to prevent within-compound (flavor-flavor) associations from being acquired; as such associations could cause excitation to be transferred from A to X (or from A to Y for the control conditions).

On Day 7, all rats received saccharin conditioning as on Day 1. No treatments occurred on Day 8 to allow recovery. Days $9-17$ were just like Days 3-6. The rats received $2 \mathrm{ml}$ saccharin infusions (A) followed 15 minutes later by either vinegar (PavCI group) or coffee (control group). The control group was given one vinegar exposure on Day 18. This flavor was novel for this group at this time. Since this target flavor was important for the subsequent summation test and neophobia to this flavor by the control group could obscure the summation test results, a single exposure to vinegar was given. This treatment was not expected to produce any inhibition to X (vinegar) but should reduce neophobia. On this day, the experimental group was given water in the drinking tubes to equate exposure to drinking tubes.

On Day 19 , all rats received $15-\mathrm{min}$ access to a $1 \%$ saline solution $(\mathrm{NaCl})$ followed immediately by a $0.15 \mathrm{M} \mathrm{LiCl}$ solution injected i.p. at $1.33 \%$ bodyweight. This conditioning created an excitatory CS that would be used on the summation test. No treatments occurred on Day 20. Rats were tested on Days 21 and 22; half of the rats in the PavCI group (PavCI-NaCl, $n=7$ ) and half of the rats in the control group (Control-NaCl, $n=6$ ) received 15 -min access to $\mathrm{NaCl}$ (the excitor) during the summation test exposures. The remaining rats (PavCI-Comp and Control-Comp, $n \mathrm{~s}=7$ ) received a compound test CS ( $\mathrm{NaCl}$ combined with Vinegar) as their summation test stimulus. CI is evident to the 
extent that rats consume less of the compound CS than the salt solution alone. The PavCI groups were expected to exhibit such an effect while the control groups were not.

Results and Discussion. This experiment provided some evidence that a CS given Pavlovian CI training passes a summation test. On Day 1, the rats in Group PavCI consumed $($ mean + SEM) $9.5( \pm 1.0) \mathrm{ml}$ and Group Control consumed $9.8( \pm 1.4) \mathrm{ml}$. An analysis of variance (ANOVA) conducted from the data of Day 1 found that the groups did not differ in consumption $[F(1,25)=0.0, p>0.05]$. AX-noUS trials occurred on Days 3-6. On Day 3, the rats in Group PavCI consumed 3.1 ( +0.3$) \mathrm{ml}$ and Group Control consumed $3.1( \pm 0.8) \mathrm{ml}$. Consumption data from Day 3 found that the groups did not differ in consumption, $F<1.0, p>0.20$. On Day 6, the rats in Group PavCI consumed 7.3 $( \pm 1.0) \mathrm{ml}$ and Group Control consumed $3.1(+0.8) \mathrm{ml}$. On Day 7, all rats received saccharin conditioning. Group PavCI consumed $4.3( \pm 0.6) \mathrm{ml}$ and Group Control consumed $6.2( \pm 0.8) \mathrm{ml}$. An ANOVA conducted from the consumption data from Day 1 and Day 7 of the experiment found a main effect of day, $F(1,25)=34.9, p<0.001$ during these conditioning days. There was no main effect of group $[F(1,25)=0.9, p>0.1]$ nor an interaction $[F(1,25)=1.3, p>0.1]$. AX-noUS trials occurred on Days 9-17. On Day 9, the rats in Group PavCI consumed $8.6(+1.4) \mathrm{ml}$ and Group Control consumed 12.2 $(+2.0) \mathrm{ml}$.

On Day 17, the rats in Group PavCI consumed $11.0( \pm 3.0) \mathrm{ml}$ and Group Control consumed $11.0(+3.0) \mathrm{ml}$. On Day 18, Group Control received saline and consumed 9.6 $( \pm 1.1) \mathrm{ml}$. An ANOVA conducted from the consumption data from Day 3 and Day 17 of the experiment found a main effect of day, $F(1,25)=51.0, p<0.001$ during these (initial and final) AX-days. There was no main effect of group $[F(1,25)=0.9, p>0.1]$ nor an 
interaction $[F(1,25)=1.3, p>0.1]$, though. On Day 19, the rats in Group PavCI consumed $7.7( \pm 0.8) \mathrm{ml}$ and Group Control consumed $9.6( \pm 1.0) \mathrm{ml}$. Consumption on the Day 19 conditioning trial was not statistically significantly different for the conditions, $F(1,25)=2.3, p>0.1$

Day 21 and Day 22 were test days. On Day 21, the rats in Group PavCI-NaCl consumed $0.6( \pm 0.4)$ ml, Group PavCI-Comp consumed $7.7( \pm 1.1)$, Group Control-NaCl consumed $0.2( \pm 0.0)$ and Group Control-Comp consumed $7.8( \pm 1.3)$. Consumption on Day 21 was statistically significantly different for the conditions, $F(3,23)=22.7, p<$ 0.001. On this day, PavCI-NaCl significantly differed from PavCI-Comp $[F(1,12)=38.4$, $p<0.001]$, and Control-NaCl differed from Control-Comp $[F(1,11)=30.3, p<0.001]$.

On Day 22, the rats in Group PavCI-NaCl consumed $3.3( \pm 1.5)$ ml, Group PavCIComp consumed $19.6(+1.0)$, Group Control-Comp consumed $13.5(+3.5)$ and Group Control- $\mathrm{NaCl}$ consumed $2( \pm 1.0)$. Consumption on Day 22 was statistically significantly different for the conditions, $F(3,23)=13.2, p<0.001$. On this day; PavCI-NaCl significantly differed from PavCI-Comp $[F(1,12)=47.6, p<0.001]$. Control-NaCl differed from Control-Comp $[F(1,12)=38.4, p<0.001]$. 


\section{CHAPTER 3:}

\section{EXPERIMENT 2}

Experiment 1 provided evidence that the procedure used in our laboratory for producing conditioned inhibition (Pavlovian CI training) can produce a CS that passes a summation test. However, as mentioned, demonstration that training produces a true inhibitor requires that the $\mathrm{CS}$ also pass a retardation test. The present pilot experiment sought to establish that the Pavlovian conditioned inhibition procedure could produce a conditioned inhibitor that passes a retardation test.

Subjects and Apparatus. Nineteen, naïve, male, Sprague-Dawley-derived rats served as subjects. The range of the rats' body weights was $235-398 \mathrm{~g}$. All other details involving the apparatuses, and the source and care of the rats were the same as in Experiment 1.

Procedure. As seen in Table 4, on Day 1 all subjects received a $0.1 \%$ saccharin solution (A) followed by a $0.15 \mathrm{M} \mathrm{LiCl}$ solution injected i.p. at $1.33 \%$ bodyweight. No treatments occurred on Day 2, except water infusions were given in which rats received water from a syringe to acclimate the rats to the infusion procedure. On each of Days 3 7, all groups received daily infusions of $2 \mathrm{ml}$ of saccharin. Immediately following the infusion, all animals received a 15-min interval and then received a second flavor. The PavCI group $(n=10)$ received 15 -min access to a drinking tube filled with a $1 \%$ coffee solution $(\mathrm{X})$ as the second flavor. The control group $(n=9)$ received 15-min access to a control flavor (B), a 3\% vinegar solution. On Day 8, all rats received treatments that were identical to that of Day 1. No treatment occurred on Day 9. 
Days 10 - 18 were like Days 3-7. Saccharin infusion of CS A occurred, and then 15 minutes later the PavCI group received 15-min access to coffee. On these days, the treatment given the control groups was identical to that given to the rats in PavCI training, except vinegar $(\mathrm{Y})$ was given rather than coffee (A) during the 15-min access period.

The retardation conditioning trials occurred on each of Days 19 and 21. On both days, all rats received 15-min access to coffee in a drinking tube followed by an i.p. injection of a $0.15 \mathrm{M} \mathrm{LiCl}$ solution. No treatments occurred on Days 20 and 22. Rats were tested on Days 23-27 with a 15-min presentation of coffee. It is expected that our procedure would produce a CS that passed a retardation test in that the control group showed greater learning than the experimental group. All unspecified details of the procedure were the same as in Experiment 1.

Results and Discussion. This experiment provided evidence that a CS given Pavlovian CI training passed a retardation test. The rats in the experimental group consumed $8.8(+2.0) \mathrm{ml}$ on Day 1 and $2.4(+0.5) \mathrm{ml}$ on Day 8. The rats in the control group consumed $7.4( \pm 1.6) \mathrm{ml}$ on Day 1 and $2.0( \pm 3.0) \mathrm{ml}$ on Day 8. An ANOVA conducted the data from Day 1 and Day 8 of the experiment found that the groups did not differ in consumption during these conditioning days, $F<1$. On Day 10 (AX- trial for Group PavCI and AY- for Group Control), the rats in the control group consumed 15.1 $( \pm 1.3) \mathrm{ml}$ of vinegar $(\mathrm{Y})$ and rats in the PavCI group consumed $15.7( \pm 0.4) \mathrm{ml}$ of coffee (X), the target flavor. On Day 18, the rats in Group Control consumed $10.7( \pm 0.7) \mathrm{ml}$ of vinegar and rats in the experimental group consumed $11.2( \pm 0.6) \mathrm{ml}$ of coffee (the target flavor). 
On Day 19 and Day 21, both groups received conditioning trials with the coffee flavor. The PavCI group consumed $15.6( \pm 0.8) \mathrm{ml}$ and the control group consumed 19.2 $( \pm 0.6) \mathrm{ml}$ on Day 19 . The groups did not significantly differ in consumption on this day, $F(1,25)=2.3, \mathrm{p}>0.1$. On Day 21 the PavCI group consumed $11.6(+0.7) \mathrm{ml}$ and the control group consumed $1.1(+0.2) \mathrm{ml}$ of coffee. The groups did not significantly differ in consumption on this day, $F<1$. Slow reconditioning for Group PavCI was already evident after the first retardation pairing and was exhibited on Day 21. An ANOVA conducted from the two days (19 and 21) found a main effect of group $F(1,17)=78.7, p<0.001$; found a main effect of day $F(1,17)=252.6, p<0.001$; and an interaction $F(1,17)=72.8$, $p<0.001$. Finally, an ANOVA conducted on these data, comparing groups on all test days (Days 23-27) found a main effect of group, $F(1,17)=10.5, p<0.005$. Conditioning was stronger for the control condition than the PavCI group. This indicates the CI training produces a CS that passes a retardation test. 


\section{CHAPTER 4:}

\section{EXPERIMENT 3}

Experiments 1 and 2 showed some evidence of CI using our procedure. Earlier work (Calton et al., 1996; Schachtman et al., 2000) showed that a procedure in which a $\mathrm{CS}$ that is given extensive extinction ( 9 extinction trials) also passes a summation and retardation test. Experiment 3 explored the differences between a conditioned inhibitor produced by the Pavlovian conditioned inhibition procedure and an inhibitor produced by an extensive extinction procedure. This experiment used a retardation test.

Subjects and Apparatus. Sixteen naive, male, Sprague-Dawley rats served as subjects. The range of the rats' body weights was $185-268 \mathrm{~g}$. All other details involving the apparatuses, and the source and care of the rats were the same as in Experiments 1 and 2.

Procedure. A description of the experiment can be seen in Table 5. On each of Days 1 and 7, all rats received access to a $0.1 \%$ saccharin solution followed by an i.p. injection of a $0.15 \mathrm{M} \mathrm{LiCl}$ solution at $1.33 \%$ bodyweight. Saccharin conditioning was given to the PavCI group as "CS A" that would be used to produce inhibition for the target flavor, coffee. Saccharin conditioning was also given to the extinction group, but it served as a control treatment to ensure that all rats received comparable treatment. All rats were allowed to remain in their home cages on Days 2-6, Days 8-12, and Days 14-20 (this was to equate this procedure with planned treatments that required these days for other treatments). 
On Day 13, rats in the rats extinction group $(n=6)$ received 15-min access to a $1 \%$ coffee solution followed by a $0.15 \mathrm{M} \mathrm{LiCl}$ injection at $1.33 \%$ body weight (coffee was the target solution "X" for all rats). On Day 13, the PavCI group $(n=10)$ received 15min access to water in drinking tubes followed by the $\mathrm{LiCl}$ injection to equate exposure to drinking tubes and conditioning. All rats received oral infusions of $2 \mathrm{ml}$ of tap water on Day 21 to expose them to the infusion process. On Days $22-30$, rats in the PavCI group received oral infusions of $2 \mathrm{ml}$ of saccharin (A) followed 15 minutes later by 15 min access to coffee $(\mathrm{X})$. Rats in the extinction group received only 15-min access to coffee $(\mathrm{X})$. On each of Days 31 and 33, all rats received a retardation conditioning trial: 15-min access to coffee followed by $\mathrm{LiCl}$ injection. On Days $35-42$, all rats received 15-min access to coffee. All unspecified details of the procedure were the same as in Experiments 1 and 2.

Results and Discussion. This experiment provided evidence that Pavlovian CI shows a strong tendency towards producing more inhibition than extinction using a retardation test. One PavCI-Vin rat had to be discarded. The rats in Group PavCI consumed $6.0( \pm 1.0) \mathrm{ml}$ on Day 1 and $1.1(+0.3) \mathrm{ml}$ on Day 7 . The rats in the extinction

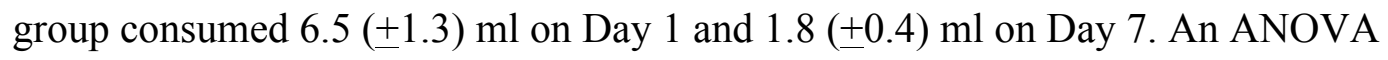
conducted on the consumption data from Day 1 and Day 7 of the experiment found a main effect of day, $F(1,17)=29.9, p<0.001$. Both groups drank significantly less on Day 7 since they were conditioned to form an aversion to this flavor. On Day 13, Group Extinction consumed $6.4( \pm 1.2) \mathrm{ml}$ of coffee solution. Group PavCI only received water on this day. Days 22-30 were extinction trials for Group Extinction and nonreinforced exposure days to the compound CS (the flavor conditioned for this group on Days 1 and 7 
along with the target flavor) for Group PavCI. On Day 22, the rats in Group Extinction consumed $1.3( \pm 0.1) \mathrm{ml}$ of the target. The rats in Group PavCI consumed $1.1( \pm 0.1) \mathrm{ml}$ of the target flavor on Day 22 (the pre-conditioned flavor, A, was infused on these days). On Day 30, Group Extinction consumed $11.4( \pm 1.5) \mathrm{ml}$ of the target and Group PavCI consumed $11.5(+1.3) \mathrm{ml}$ of the target flavor on this day. An ANOVA conducted on the data from Days 22 and 30 found a main effect of day, $F(1,15)=86.2, p<0.001$; no main effect of group, $F<1$; and no interaction, $F<1$.

On Days 31 and 33, rats in Group PavCI drank $13.3( \pm 0.9)$ and $9.1( \pm 1.1) \mathrm{ml}$ and rats in Group Extinction drank $11.6( \pm 1.0)$ and $5.1( \pm 1.3)$ ml. A comparison of consumption on Day 31 shows no difference between groups, $F(1,14)=1.3, p>0.2$. Comparing the groups' consumption on Day 33 revealed a significant difference, $F(1,17)$ $=5.9, p<0.05$. On Day 33, the PavCI groups drank significantly more, compared to the Extinction group. Days 35-42 of the experiment served as test days. A repeated measures ANOVA conducted comparing consumption between the groups from Day 35 through Day 42 , found a main effect of day, $F(7,112)=8.5, p<0.001$; no main effect of group, $F(1,16)=0.10, p>0.1$; and no interaction, $F(7,112)=1.14, p>0.1$. 


\section{CHAPTER 5:}

\section{EXPERIMENT 4}

Experiment 3 provided some evidence that more inhibition will be acquired with Pavlovian CI training than extinction. The present pilot experiment sought to determine if the Pavlovian conditioned inhibition procedure produced more or less inhibition than an extinction procedure as assessed using a summation test.

Subjects and Apparatus. Thirty-two naïve, male, Sprague-Dawley-derived rats served as subjects. The range of the body weights of the rats was $168-198 \mathrm{~g}$. The same apparatuses were used for this experiment as were used in Experiments 1-3 and the rats were obtained and maintained as in those experiments.

Procedure. On Day 1 (shown in Table 6), all subjects received a solution, Flavor A, followed by a $0.15 \mathrm{M} \mathrm{LiCl}$ solution injected i.p. at $1.33 \%$ bodyweight. No treatments occurred on Day 2 to allow the animals to recover from conditioning. This treatment was critical for the PavCI group. The procedure, on Day 3, involved exposure to a solution followed by a $\mathrm{LiCl}$ injection. On this day, the PavCI group (a total of 16 rats) received exposure to water in the drinking tube, while the extinction group (a total of 16 rats) received conditioning with Flavor X. On Day 4, all groups received infusion training with water. On Days 5-8, the rats in the PavCI group received "AX- training" (Flavor X followed by Flavor A and no $\mathrm{LiCl}$ ). Immediately following the Flavor A infusion, all animals in this group received a 15-min interval before receiving 15-min access to Flavor $\mathrm{X}$. The extinction group received $\mathrm{X}$ - training (15-min of Flavor X without $\mathrm{LiCl}$, extinction trials). 
On Day 9, all rats again received conditioning to a flavor (PavCI group received Flavor A and the extinction group received Flavor X) followed by a $0.15 \mathrm{M} \mathrm{LiCl}$ solution injected i.p. at $1.33 \%$ bodyweight. No treatments occurred on Day 10 . Treatments on Days 11-19 were identical to those of Days 5-8. On these days, the rats in the PavCI group received "AX- training" (infusion of 15-min Flavor A followed 15-min later by 15min access to Flavor $\mathrm{X}$ ) and the extinction group received $\mathrm{X}$ - (Flavor $\mathrm{X}$, no $\mathrm{LiCl}$ ). Immediately following the Flavor A infusion, all animals in this group received a 15 -min interval before receiving Flavor X. The extinction group received 15-min of Flavor X.

On Day 20 the rats were randomly placed into groups, counterbalancing for their consumption on Day 19. On Day 20, all groups received vinegar followed by a $0.15 \mathrm{M}$ $\mathrm{LiCl}$ injection. Vinegar was the flavor that was trained as an excitor to be used on the subsequent summation test. No treatments occurred on Day 21. Days 22 and 23 were test days. For half of the rats (groups PavCI-Comp, $n=8$ and Ext-Comp, $n=8$ ), a vinegarFlavor X simultaneous compound CS was presented for 15-min. The remaining rats (Groups PavCI-Vin, $n=7$ and Ext-Vin, $n=8$ ) were tested on the vinegar flavor alone. All procedural details not specified were the same as in Experiments 1-3.

Results and Discussion. This experiment provided evidence that Pavlovian CI training produces more inhibition than extinction as assessed using a summation test. The rats in Group PavCI consumed $6.6(\underline{+2.2)} \mathrm{ml}$ on Day 1 and Group Extinction consumed $6.5( \pm 1.3)$. A comparison on Day 1 of the experiment found that the groups did not differ in consumption, $F<1$. On Day 3, Group Extinction consumed $5.4( \pm 0.7) \mathrm{ml}$ of solution. Group PavCI only received water on this day. Days 5-8 were extinction trials for Group Extinction and nonreinforced exposure days to the compound CS (the flavor conditioned 
for this group on Day 1 along with the target flavor). On Days 5 and 8, the rats in Group Extinction consumed $1.8( \pm 1.3) \mathrm{ml}$ and $2.8( \pm 0.6) \mathrm{ml}$. The rats in Group PavCI consumed $2.5( \pm 0.5) \mathrm{ml}$ and $2.3( \pm 0.5) \mathrm{ml}$.

On Day 9, the rats in Group Extinction consumed 1.2 (+0.4) ml. The rats in Group PavCI consumed $5.0( \pm 1.0) \mathrm{ml}$ of the target flavor on Day 9 (the pre-conditioned flavor, A, was infused on these days). Extinction trials occurred on Days 11-19 for Group Extinction; and nonreinforced exposure to the compound CS (the flavor conditioned for this group on Day 1 along with the target flavor) occurred for PavCI groups. On Days 11 and 19, Group Extinction consumed $4.5( \pm 1.1) \mathrm{ml}$ and $13.2( \pm 1.6)$ $\mathrm{ml}$ and Group PavCI consumed $4.2( \pm 0.1) \mathrm{ml}$ and $10.9( \pm 0.7) \mathrm{ml}$ on this day.

An ANOVA conducted on the data from the first and last day of extinction found that both groups did increase consumption from Day 11 to the consumption of Day 19, $F(1,30)=72.6, p<0.001$. Consumption on the Day 20 conditioning trial with vinegar was not statistically significantly different for the two conditions, $F<1$. An ANOVA conducted on the consumption between groups from test days Day 22 and Day 23 found a main effect of day, $F(1,30)=63.5, p<0.001$; no main effect of group, $F(1,30)=2.41, p$ $>0.05$; and an interaction occurred, $F(1,30)=6.70, p<0.02$.

An ANOVA conducted on the consumption between groups PavCI-Comp and PavCI-Vin across test days (Day 22 and Day 23) found a main effect of day, $F(1$, $14)=83.0, \mathrm{p}<0.001$; main effect of group, $F(1,14)=19.0, \mathrm{p}=0.001$; and an interaction, $F(1,14)=15.7, \mathrm{p}=0.001$. An ANOVA comparing consumption between groups Ext-Comp and Ext-Vin across test days (Day 22 and Day 23) found a main effect 
of day, $F(1,14)=26.5, \mathrm{p}<0.001$. A comparison of groups Ext-Comp and PavCI-Comp across two test days found a main effect of day, $F(1,14)=103.0, \mathrm{p}<0.001$; main effect of group, $F(1,14)=6.4, \mathrm{p}<0.05$; and an interaction, $F(1,14)=11.3, \mathrm{p}<0.01$. On both test trials, the PavCI groups revealed better evidence of the target flavor passing the summation test than the extinction groups. 


\section{CHAPTER 6:}

\section{EXPERIMENT 5}

We know from Experiments 1 and 2 that conditioned inhibition training produces a conditioned stimulus that passes both the retardation test and the summation test. Previous research (Calton et al.1998; Schachtman et al. 2000) shows that an extinguished conditioned stimulus can also pass both the summation test and the retardation test. Experiment 4 has shown that inhibition is greater when following a Pavlovian conditioned inhibition procedure compared to extinction. However, Experiment 3 sought to compare extinction and Pavlovian conditioned inhibition training in a retardation test. Yet, the experiment was not entirely convincing.

The focus of the present dissertation was Experiment 5. This experiment was expected to help resolve the issue regarding which procedure produces the most inhibition. Experiment 5 improved upon Experiment 3 in two ways. First, the flavors (saccharin and coffee) were not counterbalanced for the roles they served in the study in Experiment 3. So, Experiment 5 did counterbalance these two flavors for the roles they served. Second, the procedure for Experiment 3 held many "no treatment" days; these were removed from the design of Experiment 5. In sum, Experiment 5 sought to confirm the finding in Experiment 3 that the Pavlovian conditioned inhibition procedure produces more inhibition than extinction, when compared using a retardation test.

Subjects and Apparatus. Sixteen naive, male, Sprague-Dawley rats served as subjects. The range of body weights at the start of the study was 186-211g. All other 
details involving the apparatuses, and the source and care of the rats were the same as in Experiments 1-4.

Procedures. The design of the experiment can be seen in Table 7. All procedures of Experiment 5 were identical to those in Experiment 3, with one exception as mentioned: the flavors (saccharin and coffee) were counterbalanced for the role they served.

All rats were exposed to the infusion process, with water in a needleless syringe, prior to the start of the experiment. On Day 1, half of the rats in Groups PavCI and half of the rats in Group Extinction received access to a $0.1 \%$ saccharin solution followed by an i.p. injection of a $0.15 \mathrm{M} \mathrm{LiCl}$ solution at $1.33 \%$ bodyweight. The other half of the rats received access to a $1 \%$ coffee solution followed by this $\mathrm{LiCl}$ injection. No nominal events occurred on Day 2 to allow the rats to recover from the conditioning. Day 3 was identical to Day 1; all rats were conditioned on their respective flavors. On Day 5, all rats received another conditioning trial with an i.p. injection and the same flavors they were conditioned with on Days 1 and 3. Three conditioning trials were used since flavor consumption was anomalously low on these trials and we sought adequate conditioning on those A+ trials. Day 7 was a conditioning day with presentation of a solution not received on Days 1, 3, and 5, followed by an i.p. injection of a $0.15 \mathrm{M} \mathrm{LiCl}$ solution at $1.33 \%$ bodyweight. On day 7 , Group PavCI $(n=8)$ was conditioned with water and Group Extinction ( $n=8)$ was conditioned with saccharin or coffee (counterbalanced). No treatments occurred on Day 8. 
On Days 9 - 21, the rats in Group PavCI received two flavors. The first flavor they received each day was the solution they had received on Days 1, 3 and 5 . The second flavor given on Days 9-21 was the potential inhibitory flavor. Rats in Group PavCI received oral infusions of $2 \mathrm{ml}$ of the flavor they had received in the initial phase of the experiment (e.g., coffee) followed 15 minutes later by 15-min access to a novel flavor (e.g., saccharin). On each of Days 9-21, the rats in Group Extinction received a 15-min exposure to the same flavor that they had received on Day 7. This flavor was the potential inhibitor for this group.

On Day 22, all rats received a retardation/reconditioning trial: 15-min access to the flavor serving as the potential inhibitor followed by the same $\mathrm{LiCl}$ injection used in earlier phases of the study. No nominal treatments occurred on Day 23. On Days 24-27, all rats were exposed, for 15 minutes, to the flavor serving as the potential inhibitor.

Results and Discussion. The results of the experiment confirmed the findings of the earlier experiments, as there was a very strong tendency towards more evidence of inhibition for the PavCI group than the extinction group.

The rats in Group PavCI consumed $1.8( \pm 0.9) \mathrm{ml}, 0.4( \pm 0.1) \mathrm{ml}$, and $3.7( \pm 1.7) \mathrm{ml}$ on Days 1, 3 and 5, respectively. A repeated measures ANOVA was conducted on Group PavCI consumption data from Days 1, 3, and 5 of the experiment. This analysis found that the consumption did not differ over these conditioning days because consumption was so low across all three days, $F(2,14)=1.70, p>0.1$. On Day 7, Group Extinction only consumed $0.3( \pm 0.1) \mathrm{ml}$ of solution. Thus, they were able to sample the solution but very little was consumed. Group PavCI only received water on this day. 
Days 9-21 were extinction trials for Group Extinction and nonreinforced exposure days to the compound CS (the flavor conditioned for this group on Days 1, 3 and 5 along with the target flavor). On Day 9, the rats in Group Extinction consumed $0.3( \pm 0.1) \mathrm{ml}$. The rats in Group PavCI consumed $1.0( \pm 0.7) \mathrm{ml}$ of the target flavor on Day 9 (the preconditioned flavor, A, was infused on these days). On Day 21, Group Extinction consumed $3.4( \pm 1.3) \mathrm{ml}$ and Group PavCI consumed $7.6( \pm 1.4) \mathrm{ml}$ on this day. An ANOVA conducted on the data from the first and last day of extinction found that Group Extinction did increase its consumption from Day 9 consumption to that of Day 21, $F(1,14)=11.40, p<0.02$. An ANOVA conducted on the first AX-trial on Day 9 to the last AX-trial on Day 21, comparing groups, yielded a main effect of day, $F(1,14)=$ $19.40, p<0.001$, main effect of group, $F(1,14)=6.70, p<0.03$, but no interaction, $F(1,14)=1.90, p>0.1$

Consumption on the Day 22 retardation conditioning trial was not statistically significantly different for the two conditions, $F(1,14)=1.74, p>0.1$, even if the means looked numerically different: $(9.0 \pm 1.9 \mathrm{ml}$ for Group PavCI and $5.8+1.4 \mathrm{ml}$ for Group Extinction). On Day 24, a comparison of the groups revealed no significant differences in consumption, $F<1$. A comparison of Day 25 showed similar, non-significant results, $F<1$. Day 26 did show a significant difference between group consumption, $F(1,14)=$ 7.30, $\mathrm{p}<0.02$. The PavCI group $(9.0 \pm 1.4 \mathrm{ml})$ consumed significantly more flavor than Group Ext $(3.5 \pm 1.5 \mathrm{ml})$. Finally, a Day 27 consumption comparison showed no significant differences, $F(1,14)=0.8, \mathrm{p}>0.1$. 


\section{CHAPTER 7:}

\section{GENERAL DISCUSSION}

Essentially all conditioning theorists would agree that the two primary types of associations learned during classical conditioning are conditioned excitatory associations (in which the CS is referred to as a conditioned excitor) and conditioned inhibitory associations (for which the CS becomes a conditioned inhibitor). A conditioned excitor predicts that a US will occur or is likely to occur. A conditioned inhibitor predicts that a US will not occur or is unlikely to occur.

As mentioned at the beginning of this manuscript, CI has been an enigmatic conditioning phenomenon as the processes underlying inhibition have been debated (e.g., Rescorla 1969; Cotton et al., 1982; Miller \& Matzel, 1987). What kind of association underlies CI? If there are many ways to train a CS as an inhibitor, are there different kinds of associations underlying the different ways that CI can be produced? Can conditioned excitation (described below) and CI exist for a given CS (cf. Matzel, Gladstein, \& Miller, 1988) -- that is, can a CS have both inhibitory and excitatory properties? Can it be both a predictor of the US and a predictor of the absence of a US at the same time?

Some of these questions are relevant to the present study. First, due to phenomena such as spontaneous recovery (a retention interval causes the CR to return to an extinguished CS), it is clearly recognized that extinction does not result in the loss of the CS-US association. If such an association were lost during CS-alone extinction 
presentations, then the CR could not "recover". If extinction does not result in the loss of the CS-US association, why does the CR decrease during extinction?

Many classical conditioning researchers (e.g., Bouton, 1993, Miller, Kasprow, \& Schachtman, 1986) now acknowledge that the CS-alone extinction trials result in the acquisition of an inhibitory association (CS-noUS associations). Following an initial CSUS conditioning phase and a subsequent CS-alone extinction phase, the CS is associated with both the US (an association results that allows prediction of the US) and "noUS" (the US not occurring and an association results that allows prediction that the US will not occur).

There are two indirect tests used to determine if a CS has become a conditioned inhibitor: summation and retardation. The conditioned inhibitor can be said to pass the retardation test when there is less of a conditioned response (or slower development of the conditioned response) to the CS compared to the conditioned response (CR) of the control group. The conditioned inhibitor can be said to pass the summation test when there is less of a conditioned response to the CS (inhibitor and known excitor) compared to the CR to the excitor alone.

For a CS to be classified as a conditioned inhibitor, it must pass both the summation test and the retardation test. With these experiments, we have shown that it is possible to produce a conditioned inhibitor through Pavlovian Conditioned Inhibition Training that passes both the retardation and summation tests. 
Extensive extinction has also been shown to produce a conditioned inhibitor. Extinction involves giving CS-US pairings (X-US pairings) in which an excitatory CR develops to $\mathrm{X}$, and then giving CS-alone trials (X alone). During CS-US pairings an excitatory X-US association is acquired. Now, it is recognized that CS-alone extinction trials result the acquisition of an inhibitory association (CS-noUS associations), as first described by Konorski (1967). Following the extinction phase, the subjects may possess an X-US association and an inhibitory X-noUS association.

Calton et al. (1996) and Schachtman et al. (2000) provided evidence that an extensively extinguished CS can produce a "net" inhibitor. They claimed that, following CS-US pairings and numerous CS-alone trials, the organism may possess a CS-US association due to the pairings but, importantly, a very strong CS-noUS association due to the many extinction trials. In truth, given views by Bouton and others (Bouton, 1993; Miller et al., 1986) that extinction results in these two types of associations - but what is critical is which association is retrieved when the target CS is presented at test. If the CSUS association is retrieved, then a strong CR may occur (despite an intact CS-noUS association). If the CS-noUS association is retrieved, then a weak CR will occur (despite an intact CS-US association).

Calton et al. and Schachtman et al. made a relatively simple claim that if a CS is extinguished and the CS-noUS association is retrieved more strongly than the CS-US association, then a net conditioned inhibitor may be evident in performance (the passing of retardation and summation tests). If extinction can produce a net inhibitor, then this can mean that, if extinction treatment is extensive, extinction is a treatment that can 
produce training of a conditioned inhibitor. The effectiveness of such a treatment can be compared to other, more established treatments for producing an inhibitor.

Recent research (Bouton, 1986) has shown that an extinguished stimulus can pass a retardation test. An extinguished CS also has been shown to pass a summation test (Calton, Mitchell, \& Schachtman, 1996; Schachtman, Threlkeld, \& Meyer, 2000; cf. Aguado, de Brugada, \& Hall, 2001). Calton et al. discovered that an extinguished CS passes both a retardation test and a summation test.

If it is accepted that both the Pavlovian conditioned inhibition procedure and extinction can produce conditioned inhibition, it is valuable to ask whether one treatment is more effective at producing inhibition than the other. According to the RescorlaWagner model, if there is only one stimulus during a conditioning trial, that stimulus is readily learned about and does not have to "compete" for learning with other CSs. If there are two CSs present during a trial, the learning that occurs on that learning trial gets divided between the two CSs.

In the Pavlovian conditioned inhibition procedure, the subject, as mentioned, first receives A paired with the US and also is presented with two CSs (A and X) without the US. According to the Rescorla-Wagner model, A will lose excitatory strength on these AX-noUS trials and $\mathrm{X}$ will gain inhibitory strength on these trials. Competition occurs, however, since the more that $\mathrm{A}$ undergoes extinction, the less that $\mathrm{X}$ becomes inhibitory (and vice versa). On each trial, learning occurs to some extent, but the Rescorla-Wagner model predicts less change per trial compared to the case in which $\mathrm{X}$ is extinguished in the absence of $\mathrm{A}$. The learning on AX-trials is divided between two stimuli. 
However, with CS-alone extinction trials, only one stimulus (e.g., X) is being presented on "no US trials". This allows for more learning (about the stimulus) to occur during each trial because the total amount of learning does not have to be split with another CS (an A stimulus is not present). During an extinction procedure, the X should rapidly lose excitatory strength and/or X should rapidly acquire inhibitory strength.

This prediction favors the view that extinction will produce more CI than Pavlovian CI training. As mentioned above, extinction as a method for producing CI has one very notable drawback that is not shared by Pavlovian CI training: the putative inhibitor starts off as a conditioned excitor. In other words, one factor that favors greater expressed inhibition for the Pavlovian CI group is that X starts such training as a neutral CS. $\mathrm{X}$ is a conditioned excitor at the start of extinction trials. More inhibition might have been acquired in the latter case but it could be masked by residual excitation. In other words, $\mathrm{X}$ for the Pavlovian CI group may have acquired a moderate amount of inhibition while $\mathrm{X}$ for the extinction group may have acquired a larger amount of inhibition than the Pavlovian CI groups but the excitation for $\mathrm{X}$ in this group offsets much of the inhibition. There is evidence that a CS can possess both inhibitory and excitatory associations (Matzel, Gladstein, \& Miller, 1988). Using the right tests, one can see evidence of both associations for the same CS.

We have shown that both the Pavlovian conditioned inhibition procedure and extinction can produce conditioned inhibition and that Pavlovian CI is more effective at producing inhibition. Most conditioning researchers would predict that the Pavlovian conditioned inhibition procedure would produce more inhibition than extinction. 
Afterall, the idea that extinction can produce a net inhibitor remains controversial (e.g., Aguado et al.). According to the Rescorla-Wagner model, if there is only one CS present during a conditioning trial, that stimulus does not have to "compete" for learning with other CSs. The CS during extinction trials should acquire a great deal of inhibition if inhibition is truly obtained on such trials. If there are two CSs present during a nonreinforced trial (AX-), the learning that occurs on that learning trial should be divided between the two CSs. X should acquire less inhibition during Pavlovian CI training trials in which the two CSs occur together without the US.

One factor that favors greater expressed inhibition for the Pavlovian CI group is that $\mathrm{X}$ starts such training as a neutral CS. $\mathrm{X}$ is a conditioned excitor at the start of extinction trials. During extinction, a CS must presumably lose its excitatory strength in addition to acquiring (perhaps rapidly) inhibitory strength. Hence, at a given point of training, $\mathrm{X}$ in the case of Pavlovian $\mathrm{CI}$ training may yield a greater net inhibitor than $\mathrm{X}$ in the extinction case. More inhibition might have been acquired in the latter case but it could be masked by residual excitation. Indeed, many conditioning theorists (Matzel et al., 1988) recognize that excitation may not even be lost at all during extinction trials but, instead, only the new learning of CS-noUS associations may be acquired.

In classical conditioning there are three phenomena that include a CS that is associated with the absence of the US. This means, compared to the usual CS-US association these cases could involve CS-noUS associations. These phenomena are: extinction, conditioned inhibition, and latent inhibition. It is important to evaluate the similarities between these three effects (e.g., Kraemer \& Spear, 1992), especially if the 
competition predicted by the Rescorla-Wagner Model sheds light on the amount of inhibition that might be produced by these types of training.

The present results found that Pavlovian CI training produced more evidence of CI than extinction in Experiments 3-5. These results consistently pointed to this advantage of Pavlovian CI. The experiments had shortcomings. There were some shortcomings of the present experiments. First, we used different flavors in different roles in the various experiments; but some of the experiments did not counterbalance for the role of different flavors within a given experiment. Second, we adjusted the procedure to maximize obtaining inhibition for one type of training (e.g., giving $3 \mathrm{~A}+$ trials in Exp. 5 to create a strong excitor to produced strong inhibition to X) but these changes were not necessarily ideal for the other treatment (e.g., extinction). Finally, some effects obtained were modest in their magnitude. For instance, the CS passed a summation test in Experiment 1, but the CS for the control group also passed this test (although to a smaller extent). Despite shortcomings of this study, the data suggest more inhibition is produced from the Pavlovian conditioned inhibition procedure compared to extinction. 


\section{Works Cited}

Aguado, L., de Brugada, I., \& Hall, G. (2001). Tests for inhibition after extinction of a conditioned stimulus in the flavour aversion procedure. Quarterly Journal of Experimental Psychology, 54B, 201-218.

Bouton, M.E. (1986). Slow reacquisition following the extinction of conditioned suppression. Learning \& Motivation, 17, 1-15.

Bouton, M.E. (1993). Context, time, and memory retrieval in the interference paradigms of Pavlovian learning. Psychological Bulletin, 114, 80-99.

Calton, J.L., Mitchell, K.G., \& Schachtman, T.R. (1996). Retardation and summation tests of an extinguished conditioned excitor. Learning and Motivation, 27, 335361.

Cotton, M.M., Goodall, G., \& Mackintosh, N.J. (1982). Inhibitory conditioning resulting from a reduction in the magnitude of reinforcement. Quarterly Journal of Experimental Psychology, 34B, 163-80.

Delamater, A.R., Kruse, J.M., Marlin, S., \& LoLordo, V.M. (1986). Conditioned inhibition in taste aversion learning: Testing methodology and empirical status. Animal Learning \& Behavior, 14, 6-14.

Espinet, A., Iraola, J.A., Bennett, C.H., \& Mackintosh, N.J. (1995). Inhibitory associations between neutral stimuli in flavor-aversion conditioning. Animal Learning \& Behavior, 23, 361-368.

Konorski, J. (1967). Integrative activity of the brain. Chicago: University of Chicago Press.

Matzel, L.D., Gladstein, L., \& Miller, R.R. (1988). Conditioned excitation and conditioned inhibition are not mutually exclusive. Learning \& Motivation, 19, 99-121.

Miller, R. R., Kasprow, W. J., \& Schachtman, T. R. (1986). Retrieval variability: Psychobiological sources and consequences. American Journal of Psychology, 99, 145-218.

Miller, R.R., \& Matzel, L.D. (1988). The comparator hypothesis: A response rule for the expression of associations. In G.H. Bower (Ed.), The Psychology of Learning and Motivation, Vol. 22 (pp. 51-92). Hillsdale, NJ: Erlbaum.

Rescorla, R.A. (1969). Pavlovian conditioned inhibition. Psychological Bulletin, 72, 7794. 
Rescorla, R.A., \& Wagner, A.R. (1972). A theory of Pavlovian conditioning: Variations in the effectiveness of reinforcement and nonreinforcement. In A.H. Black \& W.F. Prokasy (Eds.), Classical conditioning II: Current research and theory (pp. 64-99). New York: Appleton-Century Crofts.

Schachtman, T.R., Threlkeld, R., \& Meyer, K. (2000). Retention of conditioned inhibition produced by extinction. Learning and Motivation, 31, 283-300.

Wagner, A.R., \& Rescorla, R.A. (1972). Inhibition in Pavlovian conditioning: Application of a theory. In R.A. Boakes \& M.S. Halliday (Eds.), Inhibition and learning. (pp. 301-336). New York: Academic Press 


\begin{tabular}{|c|c|c|c|}
\hline \multicolumn{4}{|c|}{ Retardation Test } \\
\hline & Phase 1 & Phase 2 & Phase 3 \\
\hline Experimental & CI Training for $\mathrm{X}$ & X-US & Test on $\mathrm{X}$ \\
\hline Control & No critical treatment & X-US & Test on $\mathrm{X}$ \\
\hline \multicolumn{4}{|c|}{ Summation Test } \\
\hline & Phase 1 & Phase 2 & Phase 3 \\
\hline Experimental & CI Training for $\mathrm{X}$ & B-US & Test on B \\
\hline Experimental & CI Training for $\mathrm{X}$ & B-US & Test on BX \\
\hline Control & No critical treatment & B-US & Test on B \\
\hline Control & No critical treatment & B-US & Test on BX \\
\hline
\end{tabular}

Table 1. Retardation and summation test experimental layout. Experimental design for experiments using retardation and summation tests. CI training involves $\mathrm{A}$ as an excitor used to train $\mathrm{X}$ as the target inhibitor. 


\begin{tabular}{|l|l|}
\hline Experiment 1 & $\begin{array}{l}\text { Pilot experiment examining summation test performance following } \\
\text { Pavlovian CI training using a conditioned taste aversion procedure }\end{array}$ \\
\hline Experiment 2 & $\begin{array}{l}\text { Pilot experiment examining retardation test performance following } \\
\text { Pavlovian CI training using a conditioned taste aversion procedure }\end{array}$ \\
\hline Experiment 3 & $\begin{array}{l}\text { Pilot experiment examining retardation test performance comparing } \\
\text { Pavlovian CI training with extinction }\end{array}$ \\
\hline Experiment 4 & $\begin{array}{l}\text { Pilot experiment examining summation test performance comparing } \\
\text { Pavlovian CI training with extinction }\end{array}$ \\
\hline Experiment 5 & $\begin{array}{l}\text { Experiment examining retardation test performance comparing } \\
\text { Pavlovian CI training with extinction (improved design) }\end{array}$ \\
\hline
\end{tabular}

Table 2. Overview of experiments. A list of experiments and their purpose 


\begin{tabular}{|c|c|c|c|c|c|c|c|}
\hline \multicolumn{8}{|c|}{ Experiment 1 Timeline } \\
\hline & Day 1 & $\frac{\text { Days 3- }}{\underline{6}}$ & Day 7 & $\frac{\text { Days 9- }}{\underline{17}}$ & $\begin{array}{l}\text { Day } \\
\underline{18}\end{array}$ & Day 19 & $\frac{\text { Days } 21}{\frac{\& 22}{\text { (Test) }}}$ \\
\hline $\begin{array}{l}\text { PavCI- } \\
\mathrm{NaCl}\end{array}$ & Sac-LiCl & SacVin & Sac-LiCl & SacVin & Water & $\mathrm{NaCl}-\mathrm{LiCl}$ & $\mathrm{NaCl}$ \\
\hline $\begin{array}{l}\text { PavCI- } \\
\text { Comp }\end{array}$ & Sac-LiCl & SacVin & Sac-LiCl & SacVin & Water & $\mathrm{NaCl}-\mathrm{LiCl}$ & NaClVin \\
\hline Cont-NaCl & Sac-LiCl & SacCoff & Sac-LiCl & SacCoff & Vin & $\mathrm{NaCl}-\mathrm{LiCl}$ & $\mathrm{NaCl}$ \\
\hline Cont-Comp & Sac-LiCl & SacCoff & Sac-LiCl & SacCoff & Vin & $\mathrm{NaCl}-\mathrm{LiCl}$ & $\mathrm{NaClVin}$ \\
\hline
\end{tabular}

Table 3. Experiment 1 timeline. Sac $=0.1 \%(\mathrm{w} / \mathrm{v})$ saccharin solution, Vin $=3 \%(\mathrm{v} / \mathrm{v})$ apple cider vinegar solution, $\mathrm{Coff}=1.5 \%(\mathrm{w} / \mathrm{v})$ decaffeinated coffee solution, $\mathrm{NaCl}=1 \%$ saline solution. $\mathrm{LiCl}=$ injection (conditioning), $0.15 \mathrm{M}$ at $1.33 \%$ bodyweight 


\section{Experiment 2 Timeline}

\begin{tabular}{|c|c|c|c|c|c|c|}
\hline & $\underline{\text { Day 1 }}$ & $\underline{\text { Days 3-7 }}$ & $\underline{\text { Day 8 }}$ & $\underline{\underline{\text { Days }}}$ & $\underline{\underline{\text { Days }}}$ & $\underline{\underline{\text { Days 23-27 }}}$ \\
\hline PavCI & Sac-LiCl & SacCoff & Sac-LiCl & SacCoff & Coff-LiCl & Coff \\
\hline Control & Sac-LiCl & SacVin & Sac-LiCl & SacVin & Coff-LiCl & Coff \\
\hline
\end{tabular}

Table 4. Experiment 2 timeline. Sac $=0.1 \%(\mathrm{w} / \mathrm{v})$ saccharin solution, Vin $=3 \%(\mathrm{v} / \mathrm{v})$ apple cider vinegar solution, Coff $=1 \%(\mathrm{w} / \mathrm{v})$ decaffeinated coffee solution. $\mathrm{LiCl}=$ injection (conditioning), $0.15 \mathrm{M}$ at $1.33 \%$ bodyweight 


\section{Experiment 3 Timeline}

\begin{tabular}{|c|c|c|c|c|c|}
\hline & $\underline{\text { Days 1\&7 }}$ & $\underline{\text { Day 13 }}$ & $\underline{\text { Days 22-30 }}$ & $\underline{\text { Days 31\&33 }}$ & $\frac{\text { Days 35-42 }}{(\text { Test })}$ \\
\hline PavCI & Sac-LiCl & Water-LiCl & SacCoff & Coff-LiCl & Coff \\
\hline Ext & Sac-LiCl & Coff-LiCl & Coff & Coff-LiCl & Coff \\
\hline
\end{tabular}

Table 5. Experiment 3 timeline. Sac $=0.1 \%(\mathrm{w} / \mathrm{v})$ saccharin solution, Vin $=3 \%(\mathrm{v} / \mathrm{v})$ apple cider vinegar solution, Coff $=1 \%(\mathrm{w} / \mathrm{v})$ decaffeinated coffee solution. $\mathrm{LiCl}=$ injection (conditioning), $0.15 \mathrm{M}$ at $1.33 \%$ bodyweight 


\begin{tabular}{|c|c|c|c|c|c|c|c|}
\hline \multicolumn{8}{|c|}{ Experiment 4 Timeline } \\
\hline & Day 1 & Day 3 & $\frac{\text { Days }}{\underline{5-8}}$ & Day 9 & $\frac{\text { Days }}{\underline{11-19}}$ & Day 20 & $\frac{\frac{\text { Days }}{22 \& 23}}{\text { (test) }}$ \\
\hline PavCI-Comp & A-LiCl & Water-LiCl & AX & A-LiCl & $\mathrm{AX}$ & Vin-LiCl & $\operatorname{Vin}+X$ \\
\hline PavCI-Vin & A-LiCl & Water-LiCl & $\mathrm{AX}$ & A-LiCl & $\mathrm{AX}$ & Vin-LiCl & Vin \\
\hline Ext-Comp & A-LiCl & $\mathrm{X}-\mathrm{LiCl}$ & $\mathrm{X}$ & $\mathrm{X}-\mathrm{LiCl}$ & $\mathrm{X}$ & Vin-LiCl & $\operatorname{Vin}+X$ \\
\hline Ext-Vin & $\mathrm{A}-\mathrm{LiCl}$ & $\mathrm{X}-\mathrm{LiCl}$ & $\mathrm{X}$ & $\mathrm{X}-\mathrm{LiCl}$ & $\mathrm{X}$ & Vin-LiCl & Vin \\
\hline
\end{tabular}

Table 6. Experiment 4 timeline. $\mathrm{A}=$ either $0.1 \%(\mathrm{w} / \mathrm{v})$ saccharin solution or $1 \%(\mathrm{w} / \mathrm{v})$ decaffeinated coffee, $\mathrm{X}=$ either $1 \%(\mathrm{w} / \mathrm{v})$ decaffeinated coffee solution or $0.1 \%(\mathrm{w} / \mathrm{v})$ saccharin solution, $\mathrm{Vin}=3 \%(\mathrm{v} / \mathrm{v})$ apple cider vinegar solution. $\mathrm{LiCl}=$ injection (conditioning), $0.15 \mathrm{M}$ at $1.33 \%$ bodyweight 


\begin{tabular}{|l|c|c|c|c|c|}
\hline \multicolumn{5}{|c|}{ Experiment 5 Timeline } \\
\hline & $\frac{\text { Days 1, 3, }}{\frac{\& 5}{}}$ & Day 7 & Days 9-21 & Day 22 & $\underline{\text { Days 24-27 }}$ \\
\hline PavCI & A-LiCl & Water-LiCl & AX & X-LiCl & X \\
\hline Ext & A-LiCl & X-LiCl & X & X-LiCl & X \\
\hline
\end{tabular}

Table 7. Experiment 5 timeline. $\mathrm{X}=$ either $0.1 \%(\mathrm{w} / \mathrm{v})$ saccharin solution or $1 \%(\mathrm{w} / \mathrm{v})$ decaffeinated coffee $\mathrm{A}=$ either $1 \%(\mathrm{w} / \mathrm{v})$ decaffeinated coffee solution or $0.1 \%(\mathrm{w} / \mathrm{v})$ saccharin solution (counterbalanced within groups). $\mathrm{LiCl}=$ injection (conditioning), $0.15 \mathrm{M}$ at $1.33 \%$ bodyweight 


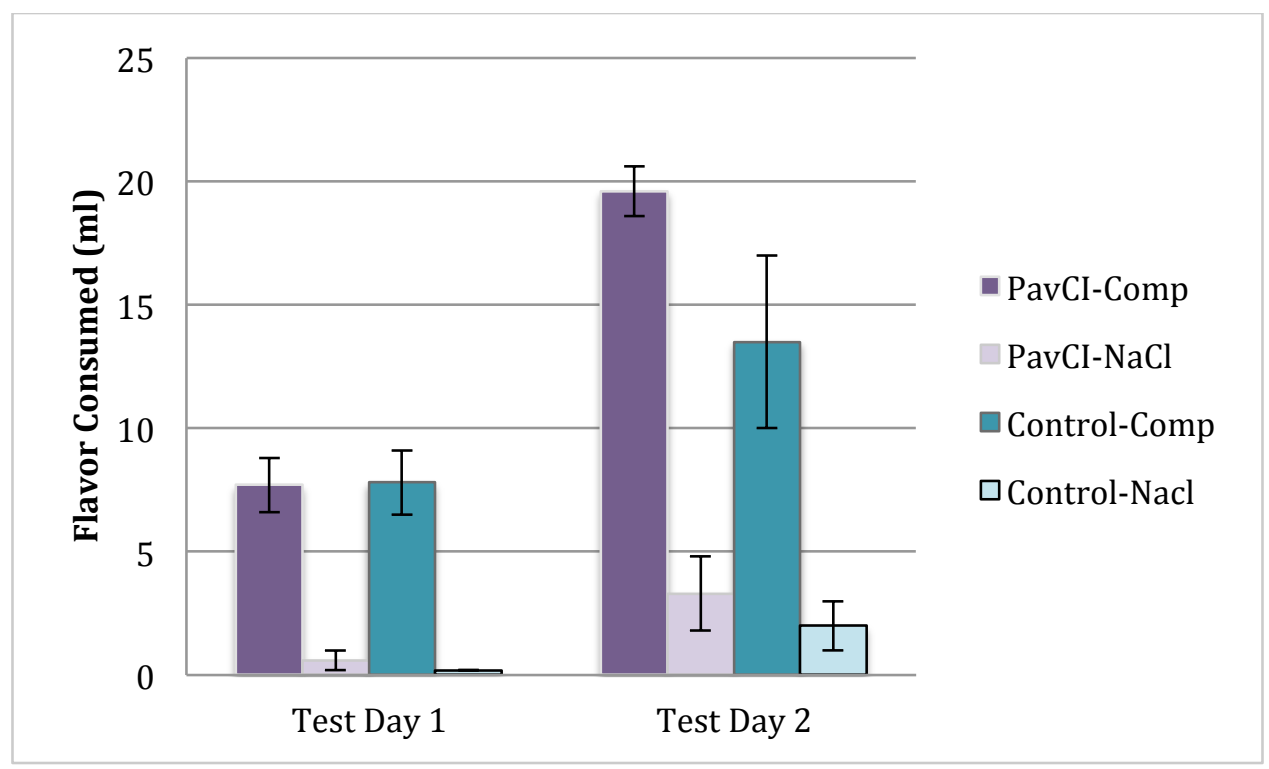

Figure 1. Experiment 1 test data. Average amount of flavor consumed (in $\mathrm{ml}$ ) by group, across two summation test days. Half of the rats in the PavCI group (PavCI-NaCl, $n=7$ ) and half of the rats in the control group (Control-NaCl, $n=6$ ) received 15-min access to $\mathrm{NaCl}$ ( $1 \%$ saline solution) during the summation test days. The remaining rats (PavCIComp and Control-Comp, $n \mathrm{~s}=7$ ) received a compound test $\mathrm{CS}, \mathrm{NaCl}$ combined with Vinegar (3\% apple cider vinegar solution), as their summation test stimulus. 


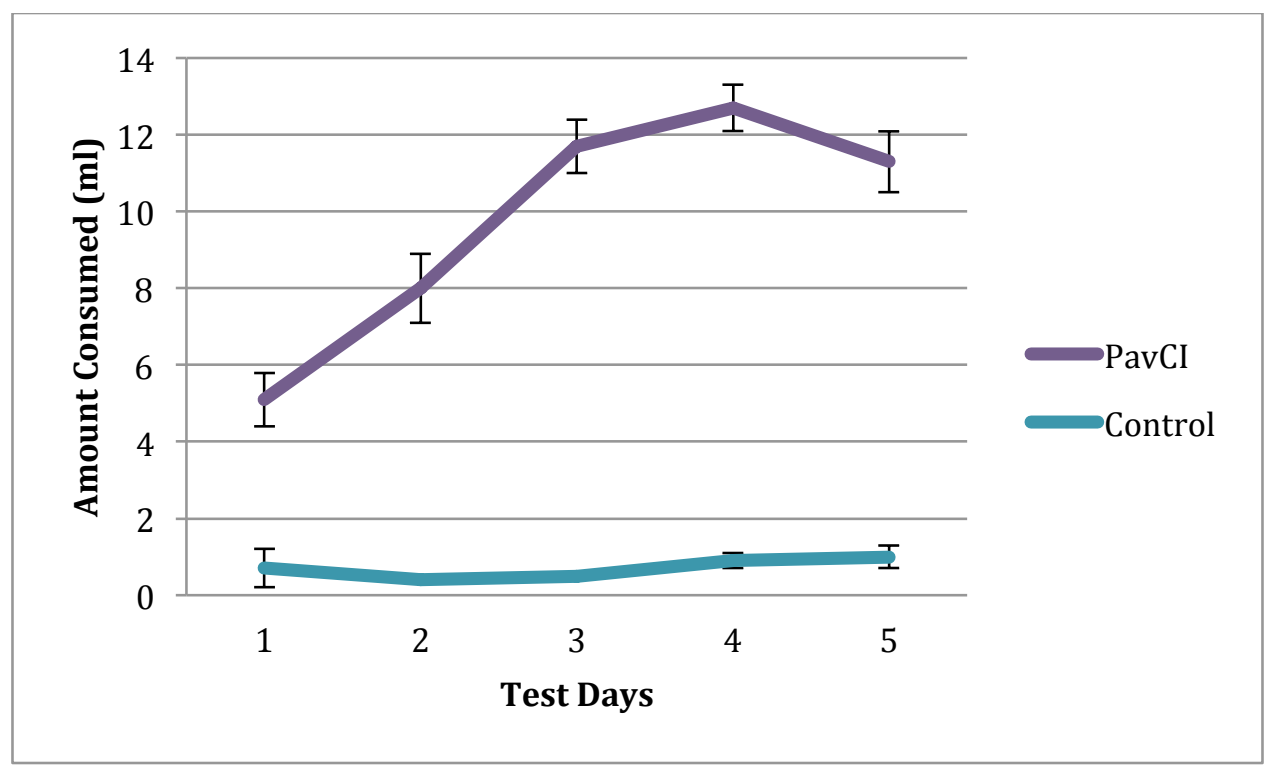

Figure 2. Experiment 2 test data. Average amount of flavor consumed (in $\mathrm{ml}$ ) by group, across five retardation test days. All groups were tested on these days with a 15-min presentation of coffee ( $1 \%$ decaffeinated coffee solution). 


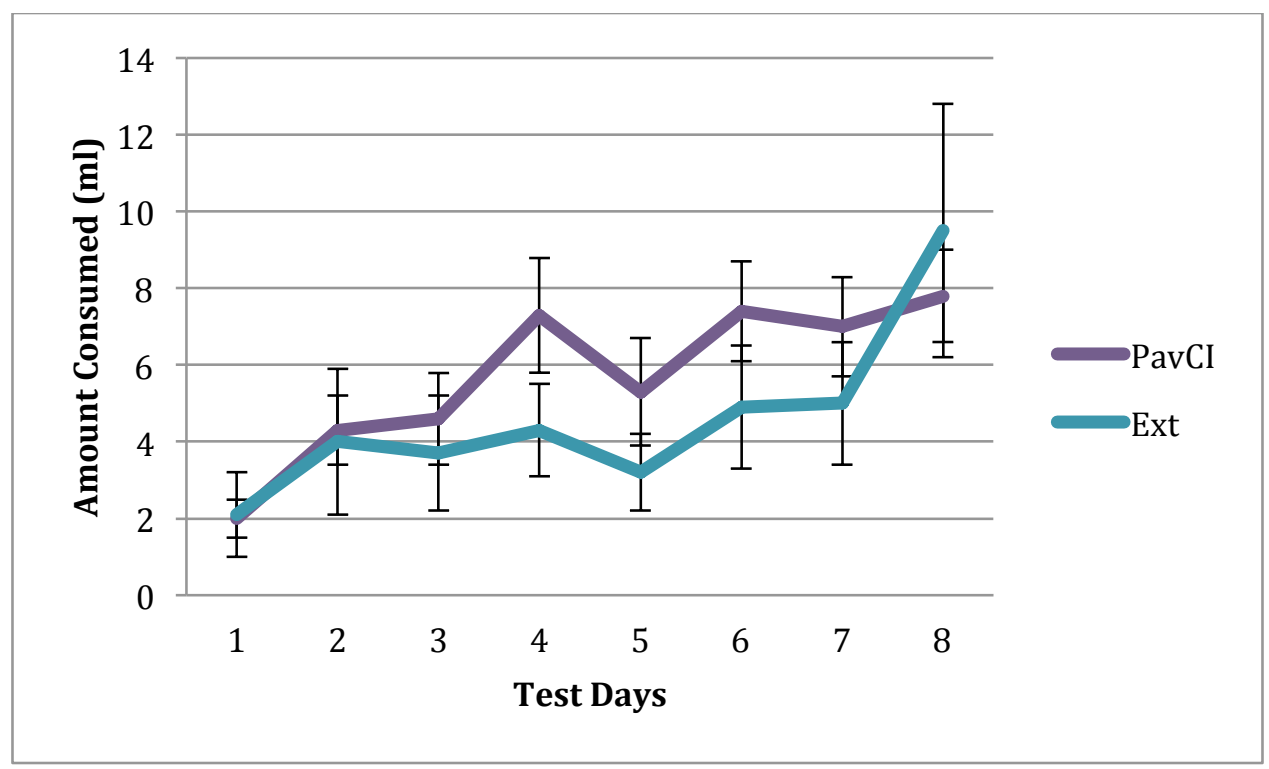

Figure 3. Experiment 3 test data. Average amount of flavor consumed (in ml) by group, across eight retardation test days. On these days, all rats received 15-min access to coffee ( $1 \%$ decaffeinated coffee solution). 


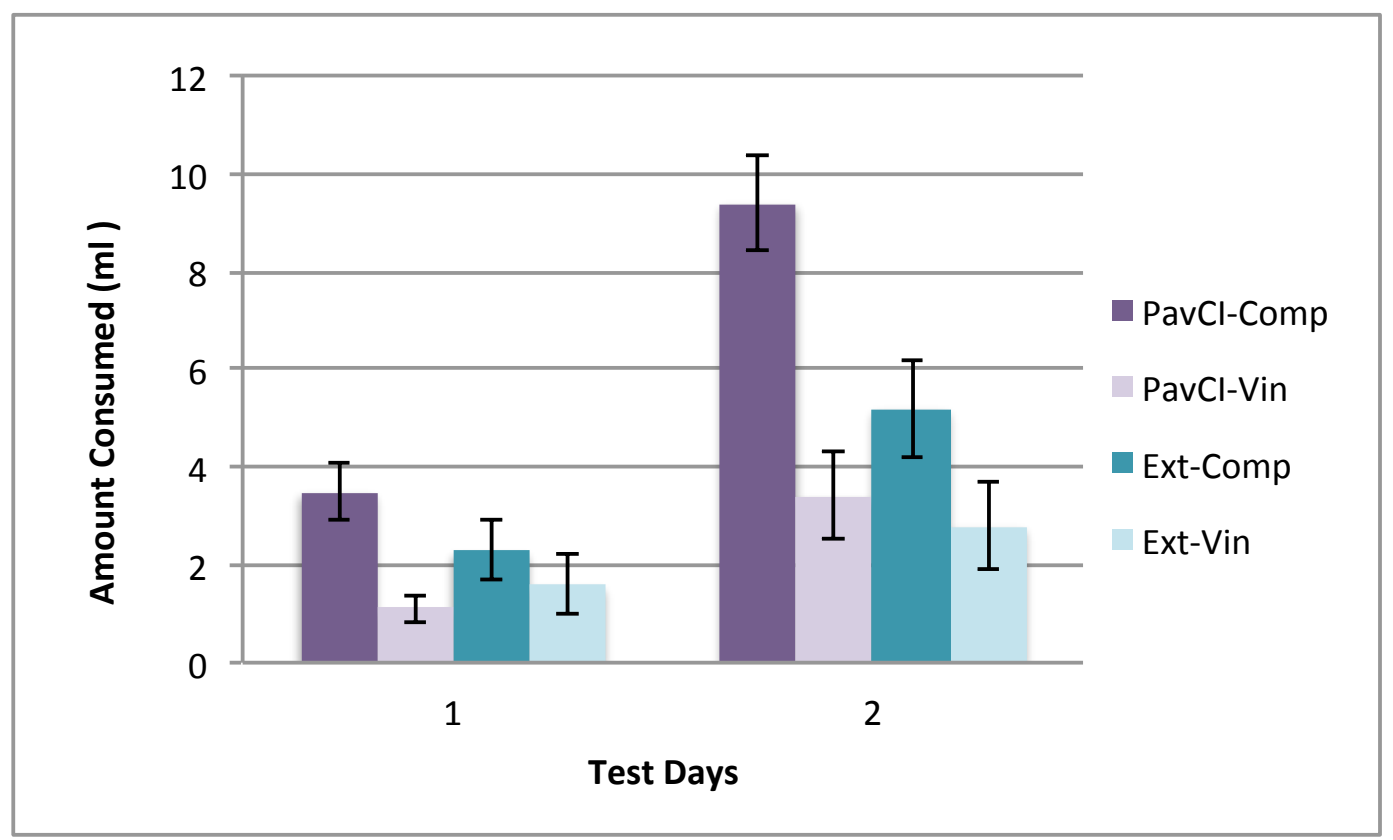

Figure 4. Experiment 4 test data. Average amount of flavor consumed (in ml) by group, across two summation test days. For half of the rats (groups PavCI-Comp, $n=8$ and ExtComp, $n=8$ ), a vinegar-Flavor X simultaneous compound CS was presented for 15-min. The remaining rats (Groups PavCI-Vin, $n=7$ and Ext-Vin, $n=8$ ) were tested on the vinegar ( $3 \%$ apple cider vinegar solution) flavor alone. $\mathrm{X}=$ either $1 \%$ decaffeinated coffee solution or $0.1 \%$ saccharin solution. 


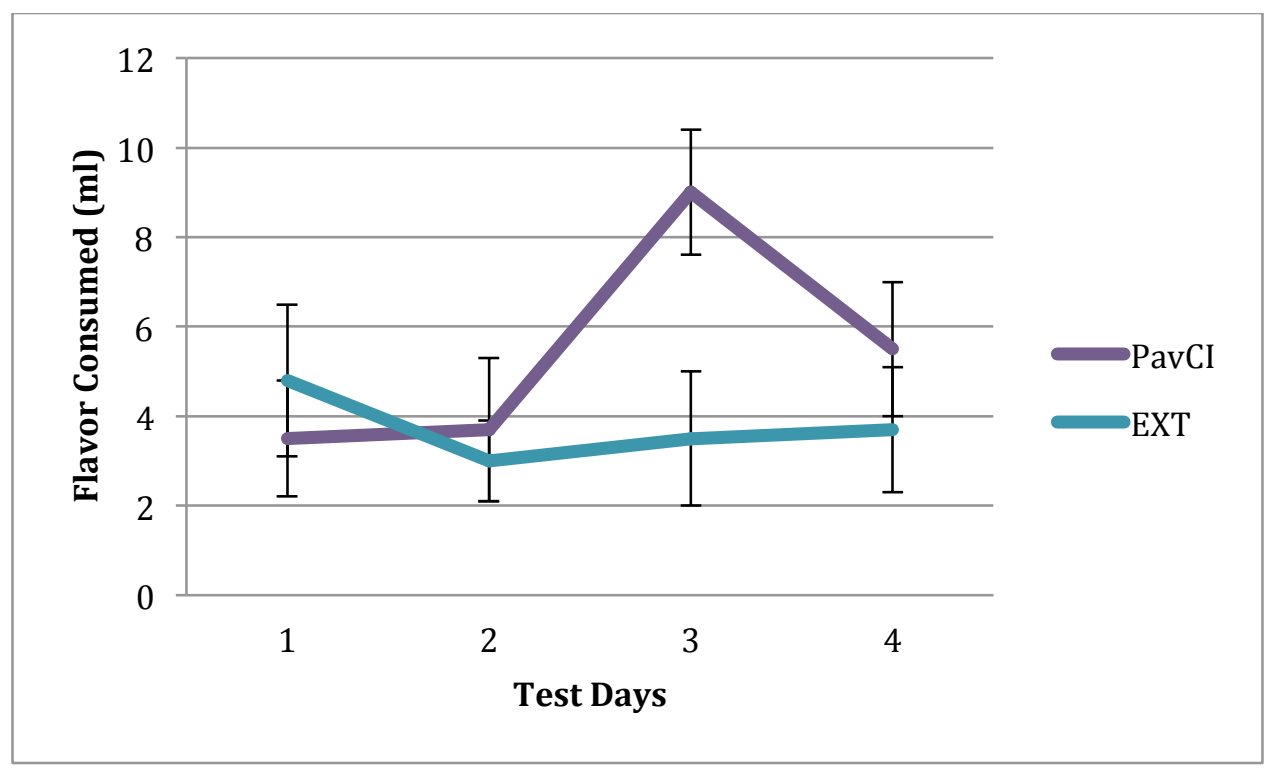

Figure 5. Experiment 5 test data. Average amount of flavor consumed (in $\mathrm{ml}$ ) by group, across four retardation test days. On these days, all rats were exposed, for 15 minutes, to the flavor serving as the potential inhibitor, Flavor X. X= either $0.1 \%$ saccharin solution or $1 \%$ decaffeinated coffee. 


\section{VITA}

Rachel Anne Richardson was born and raised in Fenton, a suburb of St. Louis, Missouri. After earning the A+ Scholarship and graduating from Fox High School in 2009, Rachel attended Jefferson College (Cum Laude). In 2013, she transferred to the University of Missouri - Columbia to complete her Bachelors degree in Psychology. Rachel then continued her studies as a graduate student at the University of Missouri, under the guidance of Dr. Todd Schachtman. In 2015, Rachel was awarded a master's degree in Cognition and Neuroscience. She went on to successfully complete her dissertation in 2019, earning a Cognition and Neuroscience PhD.

During her undergraduate and graduate career at the university, Rachel was a valued member of the Cognition and Neuroscience Lab. She was involved in research using animal models, investigating the relationship between learning/memory deficits and a variety of factors, including: Alzheimer's disease, Type II diabetes, and various nutritional/dietary interventions (such as thiamine deficiency, ketogenic diet, gluten-free diet). Rachel was also involved in other topics of animal research, heavily associated with conditioning and different processes that occur in animal learning.

During her graduate school career, Rachel attended many conferences and was an author on multiple conference abstracts each year. Aside from research, she was a teaching assistant to many professors, for many different courses. Based on student reviews, Rachel excelled as a professor when she taught her own course, for the first time in 2017. 